\title{
Impact of New Tax System on Zhengzhou Cross-border E-commerce and Innovation Strategy
}

\author{
Fan Zhang \\ College of Finance and Economics, Zhengzhou University of Science and Technology, Zhengzhou, 450064, \\ China
}

Keywords: Cross-border e-commerce, Tax revenue deal, Regulatory change, Zhengzhou bonded, Adjust and innovate

\begin{abstract}
The new policy on the import tax of cross-border e-commerce retail formally implemented on April 8, 2016 has brought about a complete shock to the cross-border e-commerce market in China, especially for the cross-border bonded mode. The New Deal broke the cross-border bonded imports in the import retail industry in the absolute superiority of the situation from the tax level, posed new challenges to Zhengzhou as the representative of the entire range of customs supervision of online shopping distribution center.
\end{abstract}

Based on the current situation of cross-border e-commerce development in Zhengzhou, this paper analyzes the impact of the new tax system on the development of cross-border e-commerce in Zhengzhou and explores the problems arising from the development of cross-border e-commerce in Zhengzhou. Based on the policy change and the innovation of public service functions, it motivates a new pattern of cross-border e-commerce development. Through scientific and timely adjustment of commodity structure, the paper hopes to enrich the development mode of cross-border e-commerce, enhance the channel integration ability in the supply chain, stimulates the rapid growth of local cross-border e-commerce enterprises and enhances the influence of Zhengzhou on the incubation of rules in the new era of cross-border electricity suppliers.

\section{Introduction}

Since May 2012, approved by the National Development and Reform Commission, Zhengzhou has become one of the first batches of pilot cities for cross-border e-commerce in the country. Relying on its geographical location and resource advantages, with the innovation in regulatory mode and development mode, the volume of cross-border e-commerce business in Zhengzhou has been increasing year by year, making it a new growth point for the import and export of Henan Province and the whole country. As of November 12, 2015, 908 customs filing enterprises in Zhengzhou have been piloted, of which 485 are e-commerce, 271 are network operators, 89 are warehousing enterprises, 20 are logistics enterprises, 15 are customs brokers and 28 are paying enterprises. As of the end of 2017, the transaction volume exceeded 10 billion yuan. As a pilot project of cross-border e-commerce in Zhengzhou, while obtaining objective business volume and regulatory efficiency improvement, it also showed its development characteristics - mainly the bonded business model.

The promulgation and implementation of the new tax and cross-listing of cross-border e-commerce in April 2016 appear to be a hedge against cross-border e-commerce in a crazy scenario. For self-operated bonded platforms, the sales volume of many cross-border e-commerce enterprises is shrinking substantially overnight. In addition, the announcement of a positive list and the large quantity of products are off the shelf, pushing cross-border e-commerce enterprises to the cusp of development in the industry.

Although the State Council executive meeting on September 20, 2017 approved the extension of the regulatory policy on the import of cross-border e-commerce retail imports, the tightening of 
cross-border e-commerce policies will not change and preventing risks in the industry and balancing various types of imports trade development model are inevitable trend.

\section{The Specific Content of the New Deal of Cross-Border E-Commerce}

\subsection{Tax System}

On March 24, 2016, the Ministry of Finance, the General Administration of Customs and the State Administration of Taxation jointly announced that since April 8, 2016, a new tax system for the import of cross-border e-commerce retailers will be implemented, namely the "cross-border e-commerce consolidated tax". Cross-border e-commerce retail imports according goods to the tax, within the limits of cross-border e-commerce retail imports, the tariff rate temporarily set $0 \%$, import value-added tax, consumption tax abolish exemption amount, according to the statutory tax liability of $70 \%$. Individuals who purchase goods for cross-border e-commerce retail importation as taxpayers are subject to consolidated tax at dutiable value based on the overall transaction price including the retail price of the goods, freight and insurance.

\subsection{Inventory Management System}

In coordination with the implementation of the import tax policy on cross-border e-commerce retail imports, the Ministry of Finance, the NDRC and the General Administration of Customs jointly announced to the public the "list of imported goods for cross-border e-commerce retail imports". Only those products in the list can be listed according to the cross- the way the tax system imports, other products are imported in accordance with the general trade.

\section{2016 Cross-Border E-Commerce brought about the Reform of the New Deal}

\subsection{Tax System}

The nature of cross-border e-commerce "trade in goods" has been clarified. Compared with the previous one, the overall increase in tax rate has narrowed the tax gap with general import trade and improved the arbitrage space for low-priced exemption of goods and the serious loss of tax revenues.

Cross-border electricity supplier cancels 50-yuan exemption amount. Any goods entering the territory through cross-border e-commerce require taxation at different rates. In the case of maternal and child commodities, the value of purchasing no more than 500 yuan can be exempt from tax payment when the amount of exemption is not enough.

Tax base has expanded. Cross-border electricity supplier consolidated tax base is the value of goods, logistics costs, and insurance premiums. The increase of taxes and fees will inevitably lead to the increase of the operating cost of the e-commerce enterprises, and then to the taxpayers, resulting in the rise of payment costs.

\subsection{Inventory Management System}

The Cross-border E-commerce Retail Import List of Products clearly defines the content of goods operated by cross-border e-commerce businesses and it has a disruptive effect on the customs clearance process of cross-border bonded goods entering the country. The promulgation of this policy has promoted the registration system such as formula milk powder for infants and young children, special medical uses formula food, health food, and speed up the registration of record standards and international standards of speed. The announcement of the list, while achieving efficient entry clearance, it also ensures the quality supervision of the inbound merchandise, intercepts the entry of non-retail industrial raw materials, prohibited items, and even poses a safety risk to consumers. On the one hand, the positive list of goods outside the cross-border bonded goods refused to resist; the other hand, carry out cross-border bonded business enterprises must face the new requirements of the customs clearance of goods; short-term customs clearance cannot handle the various requirements of the enterprise You need to consider building a new import trade model. 


\section{Impact of New Tax System on Cross-border E-commerce in Zhengzhou}

\subsection{Low-value High-frequency Cross-border Bonded Imports Increased Taxes}

First of all, the scope of the tax base of cross-border e-commerce consolidated tax coverage is expanding. It is the total value of goods, logistics and insurance. Second, cancel the tax exemption within 50 yuan, according to the actual tax rate charged. Take the maternal and child commodities with a high frequency of cross-border e-commerce platform as an example, compare the taxes levied before and after-tax reform as shown in Table 1.

Table 1. Maternal and Infant Goods Tax Comparison

\begin{tabular}{|c|c|c|c|c|c|c|c|c|c|}
\hline \multirow{2}{*}{$\begin{array}{l}\text { Product } \\
\text { category }\end{array}$} & \multirow{2}{*}{$\begin{array}{l}\text { Value } \\
\text { (yuan) }\end{array}$} & \multicolumn{2}{|c|}{$\begin{array}{l}\text { Old Parcel } \\
\quad \text { tax }\end{array}$} & \multicolumn{3}{|c|}{$\begin{array}{l}\text { Cross-border electricity } \\
\text { supplier consolidated tax }\end{array}$} & \multicolumn{3}{|c|}{ New Parcel tax } \\
\hline & & $\begin{array}{l}\text { tax } \\
\text { rate }\end{array}$ & Tax & tax rate & Tax & Trend & $\begin{array}{l}\text { tax } \\
\text { rate }\end{array}$ & Tax & Trend \\
\hline \multirow{5}{*}{$\begin{array}{l}\text { Mother } \\
\text { and baby } \\
\text { goods }\end{array}$} & 333 & $10 \%$ & 0 & $11.9 \%$ & 39.6 & & $15 \%$ & 0 & \\
\hline & 350 & $10 \%$ & 0 & $11.9 \%$ & 41.7 & & $15 \%$ & 52.5 & \\
\hline & 400 & $10 \%$ & 0 & $11.9 \%$ & 47.6 & & $15 \%$ & 60 & \\
\hline & 500 & $10 \%$ & 0 & $11.9 \%$ & 59.5 & & $15 \%$ & 75 & \\
\hline & 1000 & $10 \%$ & 100 & $11.9 \%$ & 119 & & $15 \%$ & 150 & \\
\hline
\end{tabular}

Table 1 shows that maternal and baby commodities with purchase value less than 333 yuan, due to the existence of tax allowances, the cost of taxes and charges for entry and exit by post and post is lower than the cross-border e-commerce comprehensive tax. This is also the region where the value of imports of cross-border e-commerce retail orders is more concentrated.

\subsection{The Inventory System Raises the Threshold of Goods Entering the Bonded Warehouse}

The publication of the "Cross-Border E-Commerce Retail Import List of Products" policy indicates that cross-border bloodedness is no longer a "free market" and many products on the cross-border e-commerce platform will face shelves. For the first time the provisions of imported cosmetics must be approved by the State Food and Drug Administration issued a permit cosmetic. Medical equipment, special foods (health products, special medical uses of food, etc.), infant formula milk powder and other commodities are subject to the State Food and Drug Administration registration record. Related products manufacturers need to go through a long registration process and high cost of clinical trials to obtain certification through the nuclear inspection, not within the deadline to obtain the relevant registration certificate and permit the approval of the goods will be considered outside the list, cannot enter Free Trade Zone.

\subsection{Tax Reform Promotes Cross-Border E-Commerce Business Model Diversification and Service Upgrades}

The new tax policy promulgated so that cross-border e-commerce industry reshuffle. The original business model with absolute advantages faced challenges. Emerging cross-border e-commerce consumption patterns such as overseas direct mail, C2C buyers, overseas direct seeding, O2O, etc. have stimulated innovation in cross-border e-commerce operation and management and brought consumers more diversified choice and higher quality shopping experience.

\section{The Cross-border E-commerce Pilot Problem Analysis in Zhengzhou}

\subsection{Local Cross-border E-commerce Enterprises overall competitiveness is Not Strong}

Cross-border e-commerce in Zhengzhou emerged a number of local enterprises such as Wan Guo 
You Pin, Zhong Da Men, No. 9 Branch, etc. with the approval of the pilot cities and the construction of the comprehensive pilot area. However, no matter the flow of traffic or orders cannot compete with foreign companies.

The reasons for the above phenomenon are many, such as website brand is not strong, the business model is lack of innovation, the lack of sound business support services, and commodity prices are not competitive. This will lead to excessive reliance on the introduction of external resources such as platform resources, financial disbursement and supply chain service resources in the construction of the Zhengzhou Cross-border E-commerce Comprehensive Zone in the future. As a result, the policy dividend and the superior resources in the region did not fully benefit the local enterprises, but were distributed.

\subsection{The Response Mechanism of Policy Change Needs to Be Further Improved}

Zhengzhou has been at the forefront of building cross-border e-commerce infrastructure projects, but lacks a unified and innovative first-line plan for the implementation of its specific implementation rules.

The explosive growth of cross-border e-commerce activities underscores the loopholes in regulatory mode. Accompanied by many problems, such as product origin is not clear, the product information is not clear. A large number of cross-border e-commerce products and people's daily lives and life and health are closely related to the promotion of quality at the same time, the quality of supervision is more important. At this stage, online cross-border goods purchased by consumers usually show the delivery position. Once the quality of the goods sold out is in question, the bonded warehouses in this area cannot escape the responsibility of supervising the failure.

\subsection{Cross-border E-commerce Supply Chain Has Weak Links}

As a distribution center for cross-border online shopping products, Zhengzhou is at the top level in China for the construction of logistics and distribution links. However, risks in cross-border e-commerce industries exist everywhere.

\section{The Cross-border E-commerce Restructuring and Innovation Strategy in Zhengzhou}

\subsection{Adjust and Optimize the Product Structure and Business Model of Local Cross-Border E-Commerce Platforms}

Policy changes are intended to balance the development of various modes of entry trade, so different methods of customs clearance have different advantages and there are applicable categories of goods. For example, high margin products suitable for general trade access are eligible for general trade; cross-border bonded goods are eligible for products with positive consumer list in milk powder, nutraceuticals, food and cosmetics, etc. For the first time, it is suitable for innovative products such as overseas live broadcasting and O2O. Innovative platforms for cross-border e-commerce companies can plan and select based on their capital and operational strength, cross-organizationally and highlight their business characteristics.

\subsection{Improve Cross-border E-commerce Regulatory System and Approval Process}

The establishment of cross-border e-commerce product source tracking platform to provide consumers with an official credible permit "inspection" query platform to change the previous consumer commitment to cross-border e-commerce "bonded warehouse delivery" lack of official channels confirmed, only through the logistics company's order to confirm the status quo.

Cross-border e-commerce activities require the integration of international business resources such as manufacturing, procurement, logistics and distribution, fund settlement and financial enhancement, attracting international companies to sit in the comprehensive study area, enriching the cross-border e-commerce supporting resources, improve the facilitation of cross-border trade and reduce operating costs while meeting the unique consumer expectations for cross-border 
e-commerce.

\subsection{Strengthen Cooperation in the Supply Chain and Enhance Its Ability to Resist Policy and Market Risks in the Future}

Through the implementation of the New Deal, the price advantage of cross-border e-commerce is shifting, but the comprehensive advantages in the future will gradually converge and emerge. How to win from the win in the price to win the quality and service, the limited resources to maximize efficiency, relying solely on the platform itself cannot be achieved, the integration of supply chain resources, strengthen cooperation in the supply chain and establish a plan from the procurement, marketing, logistics, Sale, financing and other complete supply chain system to achieve information sharing and enhance supply chain flexibility. For example, with the brand effect of the platform enterprises, the Company signed the cooperation agreement on product traceability and sales return with overseas suppliers, set up investment and financing channels to improve capital turnover and efficiency, build overseas storage bases with overseas logistics enterprises, and other measures to bring the scale effect and resist the market and the risks of policy fluctuations. The role of the service hub and resource pooling in the Pilot Zone will be clearer.

\section{References}

[1] Li Jinlong. The Impact of the New Tax System on the Future Development of Cross-Border E-Commerce. [J]. China's Circulation Economy, 2016 (9):76-78.

[2] Zhang Fan, Wang Jianwei. Innovation and transformation of cross-border e-commerce platform enterprises under the background of New Deal [J] .Modern Economic Information, 2016 (9):89-91.

[3] Wang Wencheng, Yan An, Chang Nannan. Tax reform, cross-border electricity supplier where to go [J]. Taxation and Economy, 2017 (1): 23-25. 